\title{
Axillary Lymph Node Level I
}

National Cancer Institute

\section{Source}

National Cancer Institute. Axillary Lymph Node Levell. NCI Thesaurus. Code C123461.

Axillary lymph nodes located inferolateral to the pectoralis minor. 